\title{
COMPARAÇÃO GRANULOMÉTRICA DE SACAROSE OBTIDA EM CRISTALIZADOR BATELADA
}

\author{
F. H. F. CALDAS ${ }^{1}$, L. M. da $\operatorname{SILVA}^{1}$, B. L. M. FERNANDES ${ }^{1}$, D. B. QUINTINO ${ }^{1}$, e R. A. \\ MALAGONI $^{1}$ \\ ${ }^{1}$ Universidade Federal de Uberlândia, Faculdade de Engenharia Química \\ E-mail para contato: malagoni@ feq.ufu.br
}

\begin{abstract}
RESUMO - A cristalização é um processo crucial na produção industrial de sacarose, sendo também uma das mais antigas operações da Engenharia Química. Essa operação é realizada em cristalizadores, sendo definida como a transferência de moléculas de um soluto dissolvido em uma fase líquida para uma fase sólida. $\mathrm{O}$ objetivo deste trabalho consiste em comparar a granulometria da sacarose produzida em laboratório, através de um cristalizador batelada com agitação do tipo pratos perfurados, com a sacarose comercialmente vendida. Para isso foi feito peneiramento do açúcar comercial $\left(\right.$ Caeté $\left.^{\circledR}\right)$ com peneiras de tamanho Tyler 12 a 28 e foi obtido um diâmetro médio de Sauter de $0,408 \mathrm{~mm}$. Para a determinação do diâmetro dos cristais produzidos em laboratório, foi realizado um planejamento com 17 experimentos e foi obtida a melhor condição dessa operação. Nesta condição, foram realizados três experimentos para posterior determinação dos diâmetros médios de Sauter. O diâmetro médio desses cristais demonstrou-se maior quando comparado com o resultado obtido com sacarose comercial. Os resultados sugerem que processos como estocagem e transporte podem afetar no tamanho médio dos cristais comercialmente vendidos, fazendo com que estes fiquem menores. O sistema de agitação tipo pratos perfurados também favoreceu a diminuição da camada limite do cristal favorecendo a passagem do soluto e crescimento do cristal.
\end{abstract}

\section{INTRODUÇÃO}

Atualmente, o Brasil é o maior exportador de açúcar, sendo detentor de $50 \%$ da exportação mundial conforme Unica (2013). No país, a cana-de-açúcar (Saccharum spp.) é cultivada desde o século XVI e apresenta atualmente um forte papel na economia brasileira. Existem variedades bem diferentes das pioneiras plantadas naquela época, pois, por terem sido alteradas geneticamente, as atuais possuem teores menores de fibra e maiores de açúcar (Caputo et al., 2007).

O processo de cristalização é uma importante etapa na produção de sacarose comercial, tal operação unitária vem sendo estudada por diversos pesquisadores da área como Rodrigues et al. (2003), Malagoni (2010) e Teixeira et al. (2012). A cristalização é considerada um método de baixo custo na produção de sólidos puros a partir de soluções impuras, possui vantagem de fornecer um produto de bom manuseio, fácil armazenamento e boa aparência (Mullin, 2001).

A cristalização se desenvolve por dois mecanismos básicos, sendo o primeiro a 
separação de fase, ou geração de novos cristais, tal etapa é comumente chamada de nucleação, já a segunda etapa é denominada crescimento do cristal (Myerson, 2002). O objetivo deste trabalho é comparar a granulometria do açúcar comercial com o produto obtido em um cristalizador batelada com agitação do tipo pratos perfurados, uma vez que o tamanho dos grãos varia com os métodos e variáveis envolvidas no processo.

\section{MATERIAL E MÉTODOS}

A análise granulométrica dos cristais de sacarose produzidos comercialmente foi realizada através de peneiramento do mesmo. Para o estudo da granulometria de sacarose produzida em laboratório foi preparado um Planejamento Composto Central (PCC) constituído de 17 experimentos, com o auxílio do software Statistica, versão 7.1, através do qual foi determinada a condição otimizada de produção de sacarose, para posterior análise granulométrica dos cristais obtidos através desta condição.

\subsection{Peneiramento de sacarose comercial}

Para o peneiramento do produto comercial $\left(\right.$ Caete $\left.^{\circledR}\right)$, foram utilizados peneiras circulares com aberturas de Tyler 12, 14, 16, 20, 24 e 28 e um agitador de peneiras (marca Retsch, modelo AS 200). As peneiras foram previamente limpas, secas e pesadas e, em sequência, acopladas ao agitador. A montagem estabelecida obedeceu à ordem decrescente de abertura, com a peneira de maior abertura (Tyler 12) na parte superior. A Figura 1 mostra o agitador de peneiras utilizado (A) e parte das peneiras utilizadas (B) nesta etapa.
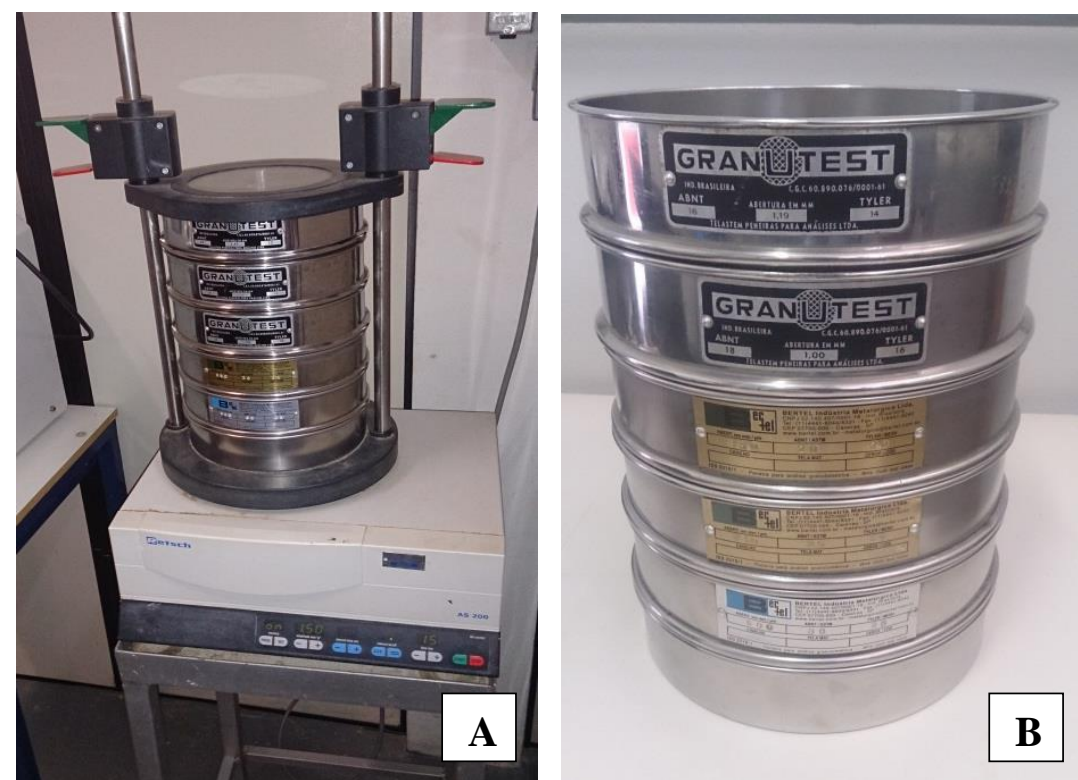

Figura 1 - Equipamentos utilizadồs no peneiramento de sacarose comercial.

Sacarose comercial foi adicionada ao conjunto e o processo de peneiramento teve duração de 20 minutos com amplitude de vibração de $1,5 \mathrm{~mm}$. Após o encerramento do processo, as peneiras foram pesadas e determinou-se assim o diâmetro médio de Sauter do 
produto comercial. O diâmetro médio de Sauter $\left(\bar{D}_{s t}\right)$ relaciona a fração mássica retida $\left(\Delta x_{i}\right)$ com o diâmetro médio da porção retida $\left(D_{i}\right)$ em mm, como mostra a Equação 1 .

$$
\bar{D}_{s t}=\frac{1}{\sum_{i=1}^{p} \frac{\Delta x_{i}}{D_{i}}}
$$

A fração mássica retida $\left(\Delta x_{i}\right)$ tem seu valor determinado através da Equação 2, onde o termo $m_{i}$ refere-se à massa de cristais retida $(\mathrm{g})$ em uma determinada peneira $i$, e $p$ representa o número de unidades de peneiras.

$$
\Delta x_{i}=\frac{m_{i}}{\sum_{i=1}^{p} m_{i}}
$$

O diâmetro médio do cristal retido em uma determinada peneira $\left(D_{i}\right)$ foi calculado através da Equação 3, onde $D_{+}$é o diâmetro de peneira imediatamente superior $(\mathrm{mm})$ e $D$. representa o diâmetro $(\mathrm{mm})$ de peneira onde os cristais foram retidos.

$$
D_{i}=\frac{D_{+}+D_{-}}{2}
$$

\subsection{Unidade Experimental}

A unidade experimental utilizada nos experimentos encontra-se no Laboratório de Cristalização da Faculdade de Engenharia Química da Universidade Federal de Uberlândia. A Figura 2 mostra os equipamentos utilizados.

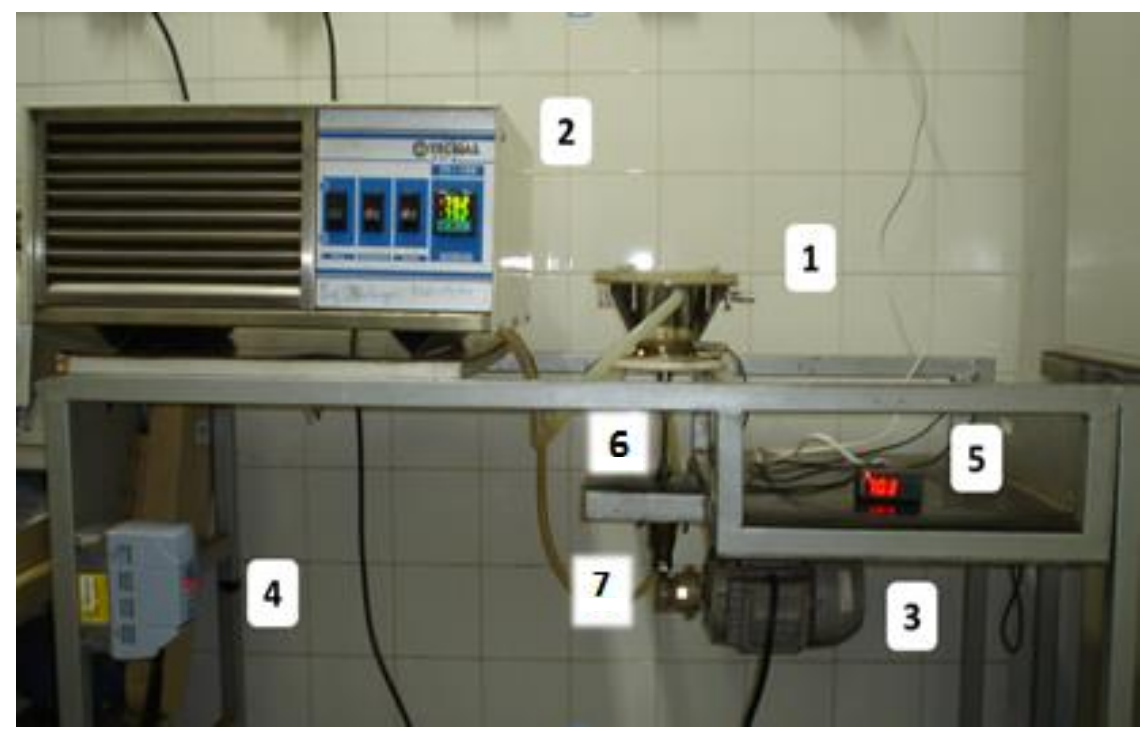

Figura 2 - Equipamentos utilizados nos experimentos de cristalização. 
Os equipamentos enumerados na Figura 2 são: 1 - Cristalizador; 2 - Banho termostatizado; 3 - Motor elétrico; 4 - Inversor de frequência; 5 - Indicador de temperatura; 6 - Excêntrico; e 7 - Eixo vibratório. O eixo vibratório e o excêntrico foram responsáveis pela transmissão da energia mecânica para o leito, gerando um movimento oscilatório. $\mathrm{O}$ motor elétrico, de marca WEG com $0,75 \mathrm{CV}$ de potência foi responsável por transmitir ao leito a energia geradora deste movimento.

A Figura 3 apresenta o interior do cristalizador, cujo formato é do tipo tronco-cônico com angulação de $65^{\circ} \mathrm{com}$ a horizontal, encamisado e fabricado em aço inoxidável. O sistema de agitação do cristalizador é a partir de pratos perfurados.

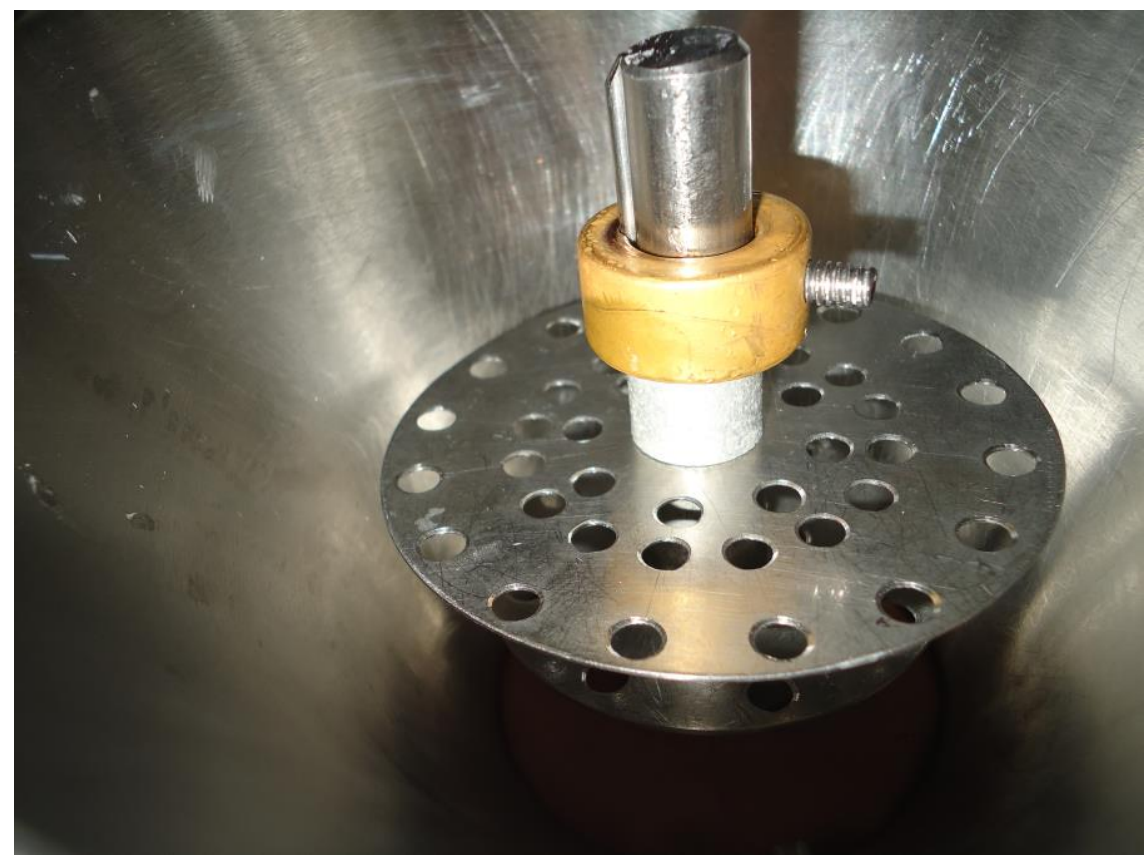

Figura 3 - Interior do cristalizador utilizado nos experimentos.

O sistema mostrado na Figura 3 é constituído por dois pratos perfurados, uma presilha e uma membrana de vedação, todos separados por anéis de alumínio. A membrana de vedação presente na parte inferior do cristalizador é feita de borracha sintética própria para o processamento de alimentos. Entre a presilha e o prato de maior diâmetro há um anel de $14 \mathrm{~mm}$. Entre os pratos perfurados de maior e menor diâmetro há um espaçamento proporcionado por um anel de $19 \mathrm{~mm}$. E entre o prato de menor diâmetro e a membrana de vedação o espaçamento é também de $14 \mathrm{~mm}$, proporcionado por um anel de alumínio. Outras medidas e especificações são descritas em Malagoni (2010).

\subsection{Experimentos de Cristalização}

O procedimento experimental adotado nos experimentos e também posteriormente na condição otimizada, foi realizado da seguinte forma: Foi realizada a montagem e ajuste de velocidade através do inversor de frequência e do tacômetro digital (Shimpo, DT - 205 B) para a velocidade de acordo com o planejamento. A solução foi preparada em banho termostatizado (Tecnal, Modelo TE 184) a temperatura de 358,5K, os dados de solubilidade 
de sacarose em água foram retirados de Oetterer (2006). Após a dissolução, coletaram-se $280 \mathrm{~mL}$ da solução e esta foi transferida para o cristalizador já previamente montado, aquecido e com agitação acionada.

Após a transferência, o cristalizador foi vedado com uma tampa de acrílico e parafusado afim de não permitir variações no interior do equipamento. Com a estabilização da temperatura em 343,15 K, foram inoculadas $12 \mathrm{~g}$ de sementes de açúcar, estas, selecionadas pelo material comercial retido na peneira de Tyler 20, após o peneiramento. Previamente à inoculação das sementes, estas foram lavadas com uma solução saturada de sacarose a 298,15 K, e após a introdução das sementes o tempo de operação começou a ser marcado.

Após o período de cristalização, a solução foi despejada na peneira Tyler 24 previamente aquecida em estufa (Medicate, modelo MD 1.3) a uma temperatura de 333,15K, separando os cristais da mistura.

A medida que os cristais foram despejados na peneira, foram borrifadas as soluções de etanol $75 \% \mathrm{v} / \mathrm{v}$ e $96 \% \mathrm{v} / \mathrm{v}$. As soluções de etanol foram utilizadas para fazer a lavagem dos cristais de sacarose, separando-os da solução, e evitando assim posterior empedramento. Esta etapa foi realizada, conforme Pereira (1997). Após a lavagem, os cristais foram colocados em vasilhames de alumínio anteriormente forrados com papel toalha e encaminhados à estufa, onde permaneceram por $48 \mathrm{~h}$ na temperatura de 333,15 K. Após todo o processo de secagem seguiu-se com a quantificação do produto obtido na cristalização através do peneiramento. $\mathrm{O}$ procedimento adotado no peneiramento é o mesmo realizado com sacarose comercial.

\section{RESULTADOS E DISCUSSÃO}

O planejamento e os resultados obtidos nos experimentos de cristalização foram analisados através do software Statistica, versão 7.1. Os resultados do peneiramento de sacarose comercial são apresentados na Tabela 3.1.

Tabela 1 - Resultados obtidos no peneiramento de sacarose comercial (Caeté ${ }^{\circledR}$ )

\begin{tabular}{|c|c|}
\hline Peneiramento & $\bar{D}_{s t}(\mathrm{~mm})$ \\
\hline 1 & 0,795 \\
\hline 2 & 0,770 \\
\hline 3 & 0,819 \\
\hline 4 & 0,808 \\
\hline
\end{tabular}

O valor médio de tamanho obtido para sacarose comercial peneirada foi de $0,798 \mathrm{~mm}$. Salienta-se que em nenhum peneiramento foi considerado o material retido no fundo do conjunto de peneiras.

A Figura 4 mostra o material comercial utilizado no trabalho e os cristais obtidos experimentalmente. 

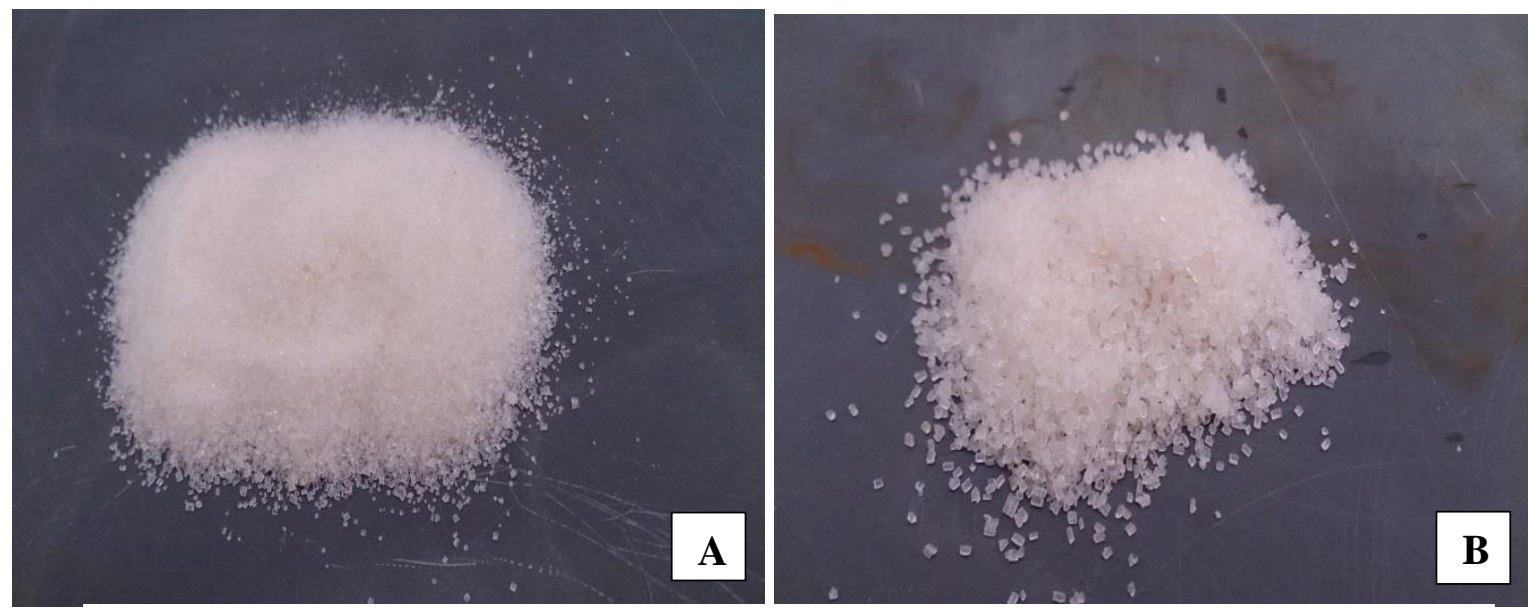

Figura 4 - (A) Material comercial utilizado; (B) Cristais obtidos experimentalmente.

Os resultados obtidos nos 17 experimentos para a resposta diâmetro de Sauter podem ser visualizados na Figura 5.

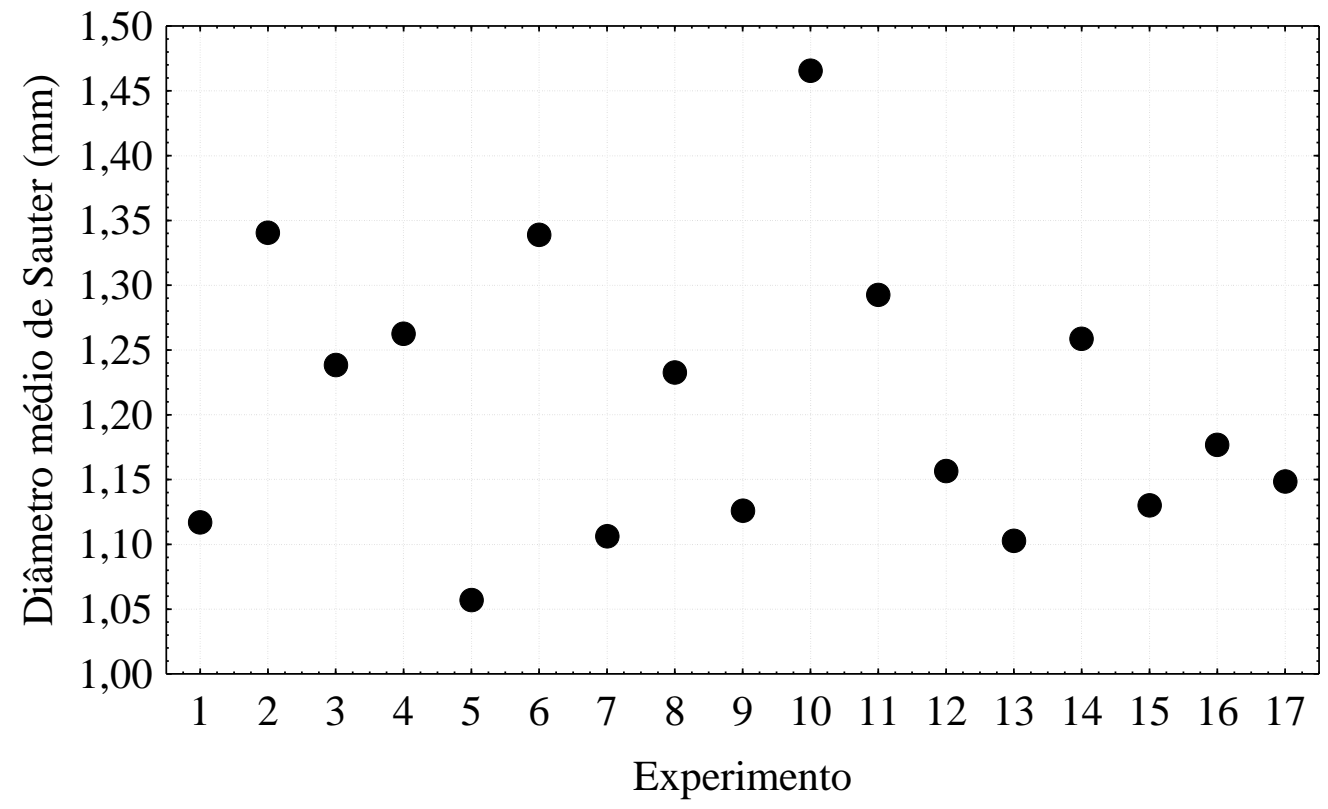

Figura 5 - Resultados obtidos para a resposta diâmetro de Sauter nos experimentos.

Em média, o tamanho do cristal alcançado nos experimentos foi de 1,186 mm e o desvio padrão obtido de $0,186 \mathrm{~mm}$. Nota-se que para o experimento número 10 , o valor encontrado é consideravelmente superior comparado ao valor obtido nas demais corridas, neste experimento foi utilizado o maior valor para a variável supersaturação e valores intermediários para intensidade de agitação e tempo de operação. $\mathrm{O}$ menor valor obtido experimentalmente refere-se ao experimento 5, no qual baixos valores de supersaturação e intensidade de agitação foram ajustados e operado um valor acima da média para a variável tempo de cristalização.

Na Figura 6, visualiza-se os resultados obtidos para a resposta produtividade. 


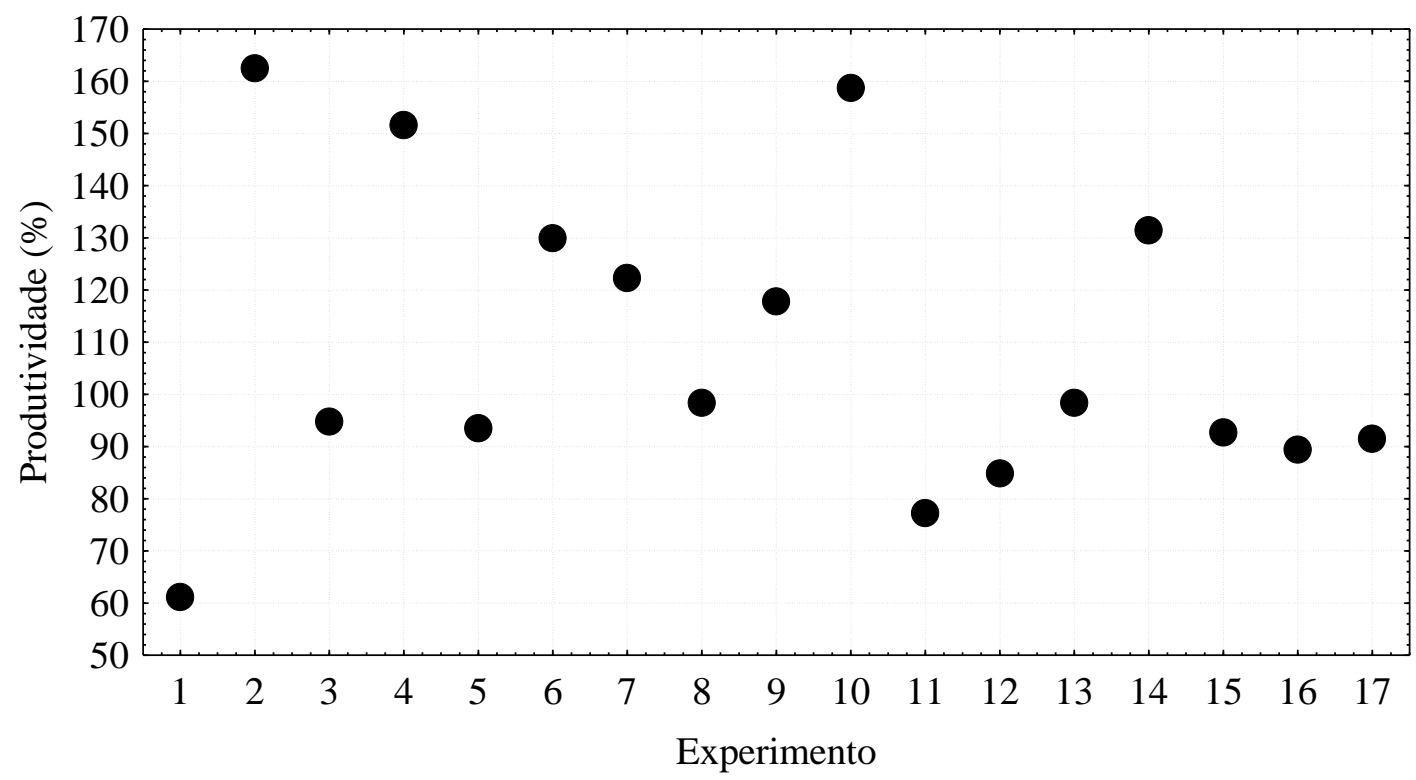

Figura 6 - Resultados obtidos experimentalmente para a resposta produtividade.

O valor médio de produtividade obtido foi de 109,18\%, observaram-se melhores respostas para os experimentos 2, 4 e 10, nos quais tiveram em comum altos valores para a variável supersaturação. De acordo com o tratamento estatístico, a condição operacional que maximiza a produtividade obtida e o tamanho médio do cristal foi de $+1,353$ para supersaturação da solução, $-0,731$ para intensidade de agitação do meio e $+0,217$ para tempo de operação.

Nestas condições foram realizados testes em triplicada, a fim de se verificar a exatidão do modelo proposto. Os testes apresentaram em média diâmetro médio de Sauter de 1,374mm e produtividade média de $159,21 \%$. O modelo previu que para esta condição otimizada uma resposta de tamanho médio de $1,467 \mathrm{~mm}$ com produtividade de $162,64 \%$, demonstrando assim que os resultados obtidos correspondem ao esperado e são consideravelmente em média maiores do que encontrados comercialmente.

\section{CONCLUSÃO}

Neste trabalho, verificou-se a maior influência da variável supersaturação comparada com as demais para as respostas de produtividade e tamanho do cristal, tal fato justifica-se pelos melhores resultados na utilização do valor máximo desta variável e pela comprovação via condição otimizada.

Nota-se também a diferença significativa de tamanho entre os cristais produzidos com o produto comercial. Tal diferença sugere que a intensidade de agitação utilizada favoreceu a transferência de massa de sacarose pela diminuição da camada limite em torno do cristal e não ocasionou choque e quebra dos cristais durante o processo de cristalização. Também foi considerada nesta comparação, a forma que a sacarose comercial é armazenada, pois no 
empilhamento de sacarias proporciona quebra dos mesmos diminuindo assim sua granulometria.

\section{REFERÊNCIAS}

CAPUTO, M. M.; SILVA, M. A.; BEAUClAIR, E. G. F.; GAVA, G. J. C. Acúmulo de sacarose, produtividade e florescimento de cana-de-açúcar sob reguladores vegetais. Interciência, vol.32, $\mathrm{n}^{\circ}$ 12, 2007.

MALAGONI, R. A. Cristalização de ácido cítrico em leito vibrado. 2010. 297 p. Tese (Doutorado em Engenharia Química) - Universidade Federal de Uberlândia, Uberlândia, 2010.

MULLIN, J. W. Crystallization. Oxford: Butterworth-Heinemann, p. 594, 2001.

MYERSON, A. S. Handbook of Industrial Crystallization, v.3, p. 313, 2002.

OETTERER, M; SARMENTO, REGITANO, d’D. M. A; SPOTO, M. H. F. Fundamentos de Ciência e Tecnologia de Alimentos. v.1, p. 135-195, 2006.

PEREIRA, A. G. Cristalização de sacarose em leito vibro - jorrado. 1997. 144 p. Dissertação (Mestrado em Engenharia Química) - Universidade Federal de Uberlândia, Uberlândia, 1997.

RODRIGUES, J. N., ANTON, C., GIOIELLI, L. A. Cristalização de lipídios estruturados obtidos a partir de gordura do leite e óleo de milho. Brazilian Journal of Pharmaceutical Sciences, vol.39, n.1, 2003.

TEIXEIRA, G. A; VIEIRA, W. F.; FINZER, J. R. D.; MALAGONI, R. A. Operational optimization of anhydrous citric acid crystallization using larger number of seed crystals. Powder Technology, v.217, p. 634-640, 2012.

UNICA. 2013. União - União da Indústria de Cana-de-açúcar. Sugarcane Industry in Brazil. 20p. Disponível em <www.unica.com.br/documentos.php>. Acessado em 10 de abril de 2014.

\section{AGRADECIMENTOS}

Agradecemos a CAPES e ao CNPq pelas bolsas de Mestrado e Iniciação Científica, respectivamente, e também à Faculdade de Engenharia Química da Universidade Federal de Uberlândia pela infraestrutura disponibilizada para a realização desta pesquisa no Laboratório de Cristalização. Agradecemos a Fundação de Amparo à Pesquisa do Estado de Minas Gerais (FAPEMIG) pelos recursos concedidos no Projeto de Participação Coletiva em Eventos Técnicos-Científicos (PCE-00082-14). 